\title{
Self-Organized Criticality of Rainfall in Central China
}

\author{
Zhiliang Wang and Chunyan Huang \\ College of Mathematics and Informatics, North China University of Water Conservancy and Hydroelectric Power, 36 Beihuan Road, \\ Henan, Zhengzhou 450011, China
}

Correspondence should be addressed to Zhiliang Wang, wzl@ncwu.edu.cn

Received 13 June 2012; Revised 28 August 2012; Accepted 16 September 2012

Academic Editor: Harry D. Kambezidis

Copyright ( 2012 Z. Wang and C. Huang. This is an open access article distributed under the Creative Commons Attribution License, which permits unrestricted use, distribution, and reproduction in any medium, provided the original work is properly cited.

\begin{abstract}
Rainfall is a complexity dynamics process. In this paper, our objective is to find the evidence of self-organized criticality (SOC) for rain datasets in China by employing the theory and method of SOC. For this reason, we analyzed the long-term rain records of five meteorological stations in Henan, a central province of China. Three concepts, that is, rain duration, drought duration, accumulated rain amount, are proposed to characterize these rain events processes. We investigate their dynamics property by using scale invariant and found that the long-term rain processes in central China indeed exhibit the feature of self-organized criticality. The proposed theory and method may be suitable to analyze other datasets from different climate zones in China.
\end{abstract}

\section{Introduction}

China is not only a big country for its population but also a big agriculture one. Rain is the main source of irrigation water, and it plays a key role in the crop growing period. No rain will cause drought while storm may cause flood. To keep sufficient agriculture production sustainable, it is necessary to identify the role of the rain clearly and to understand the characteristics of the rain deeply. In particular, analyzing the rain in central China is more important because this region is the main crop source and the population density is very high.

Rain is liquid precipitation, as opposed to nonliquid kinds of precipitation such as snow and hail and so on. Rainfall is the result of the atmosphere movement, which is influenced by sun radiation, sea water evaporation, and earth rotation. In the fact, the long-term rain record is a time series which can be regarded as a random process. The rainfall process is actually a complexity system because there are too many influencing factors.

In previous studies, many mathematical methods have been applied to find the rainfall pattern, such as periodic, trend, change point, and fractal. Based on the last 1033 years historic data set, Jiang analyzed the temporal and spatial climate variability by using a "Mexican hat" wavelet transform [1]. Bordi used Standardized Precipitation Index (SPI) to assess the climatic condition of this region and applied principal component to capture the pattern of covariability of the index at different gauge stations [2]. The results suggest that the northern part of east-central China is experiencing dry conditions more frequently from the 1970s onwards indicated by a negative trend in the SPI time series. Applying the binary cubic interpolation and optimal fitting method, Wang et al. set up a statistical model [3] and Yu used the application of gray and fuzzy methods [4], to make the rain forecast. Appling chaos dynamics theory on rainfall, Rodriguez-Iturbe et al. [5] and Wang et al. [6, 7] found that both the characteristics of the correlation integral and the Lyapunov exponents of the historical data give preliminary support to the presence of chaotic dynamics with a strange attractor. Using the correlation dimension method, the inverse approach of the nonlinear prediction method, and the method of surrogate data, Siva Kumar found that the rainfall data exhibit nonlinear behavior and possibly lowdimensional chaos, which imply that short-term prediction based on nonlinear dynamics might be possible $[8,9]$. Ramirez used a feedforward neural network and resilient propagation learning algorithm to analyze the relation between the rain data and potential temperature, vertical component of the wind, specific humidity, air temperature, 
precipitable water, relative vorticity, and moisture divergence flux [10].

All the previous works are based on an assumption that the long-term rain process is stochastic or chaotic one. Nevertheless, the rain process is located at the brink between the chaos and determination. It is necessary to develop the new theory and methodology to address this context.

In recent years, a new perspective, which is called selforganized criticality (SOC), attracted applied mathematicians, meteorologists, climatologists, and environmentalists. Self-organized criticality is proposed by Bak et al. [11-15]. The term self-organized criticality refers to the tendency of many systems driven by an energy input at a slow and constant rate to enter states characterized by scale-free behavior. The statistics of the systems then resemble those of equilibrium systems near the critical point of a phase transition. Self-organized criticality is one of a number of important discoveries made in statistical physics and related fields over the latter half of the 20th century, discoveries which relate particularly to the study of complexity in nature. The most classical instances of SOC include the common natural phenomena, such as earthquakes and avalanches [16-19]. A rainfall event can be considered as an earthquakelike or an avalanche-like event [20,21]. Further more, a longterm rain event series can be also seen as a similar event which is a complexity dynamics process and exhibits the feature of self-organized criticality.

Andrade analyzed long-term daily rain records of weather stations around the world with a special emphasis on the semiarid regions and found that there existed some evidences of SOC with these data [22]. Peters et al. investigated the European rain and fund it exhibits the feature of SOC [23-25]. However, up to now, we have not seen any report which related the China rain to SOC in the literature. In this work, we chose five meteorological stations in Henan, a central province of China, to try to find out the SOC evidence.

First of all we assume that the rainfall events that occurred in this region follow the power law distribution. And then based on the theory and method, we look for the SOC evidence through our calculating and analyzing. It is our aim for us to confirm the existence of SOC.

Henan is a leading province in grain, wheat, and oil seed output, and it is also an important producer of beef, cotton, pork, animal oil, and corn. With a population of approximately 93.6 million, Henan is the second most populous Chinese province after Guangdong. In this sense Henan is the big agriculture and population province in China. Precipitation, especially rain, has a dramatic effect on agriculture. All plants need at least some water to survive; therefore rain is important to agriculture. A regular rain pattern is usually vital to healthy plants; too much or too little rainfall can be harmful, even devastating to crops. Drought can kill crops and increase erosion while overly wet weather can cause harmful fungus growth. So studying the characteristics of the rainfall event is important to understand the dry and wet spell. It is consequently helpful to local flood and drought management.

\section{Data Sets}

We downloaded the data sets from China Meteorological Data Sharing Service System. These stations' geographic positions are displayed in Figure 1 in which Xinyang and Zhumadian are in the northern of Henan, Anyang and Zhengzhou in the northern part, Lushi in the western region. From the point of view of meteorological classification, the former two stations belong to humid subtropical climate zone while the later three stations are in the temperate climate zone.

The site name, site number, operation period and location are listed in Table 1. Station number is the general international code which is the WMO number. Obliviously the operation period is not equal in different stations. The format of degree, minute, and second is used to represent the location of the gauge station.

The original data sets should have contained the daily rain, but in some cases missing data may occur. Therefore these need to be pretreated by the method of interpolation before further analysis. After data pretreatment, we plot the five series in the Figure 2 whose horizontal axis represents the time of the rainfall day and vertical axis displays the daily rain amount $(0.1 \mathrm{~mm})$.

\section{Method of Analysis}

3.1. Scale Invariant. One of the great successes of physics in the last decades has been in the understanding of phenomena with fluctuations over many scales. In high-energy physics, critical phenomena and hydrodynamics it is often possible to establish the existence of a scaling or scale invariant regime in which the fluctuation $(\Delta x)$ in the field of interest $(x)$ at small scale $\Delta t$ and at large scale $\lambda \Delta t(\lambda>1)$ is amplified by the factor $\lambda^{-\tau}$, where $\tau$ is the scaling parameter. This may be written more concisely as

$$
\Delta x(\lambda \Delta t)=\lambda^{-\tau} \Delta x(\Delta t),
$$

where $\Delta t=t_{1}-t_{0}, \Delta x(\Delta t)=x\left(t_{1}\right)-x\left(t_{0}\right), t_{2}=t_{0}+\lambda\left(t_{1}-\right.$ $\left.t_{0}\right), \Delta x(\lambda \Delta t)=x\left(t_{2}\right)-x\left(t_{0}\right)$, and equality is understood in the sense of probability distributions, that is, $F(X)=F(Y)$ if $\operatorname{Pr}(X>c)=\operatorname{Pr}(Y>c)$ for all $c$, Pr means Probability.

In Section 1, we said that our work objective is to find the evidence of the SOC of rain process in central china. To look it out, we need construct mathematical models to mine the relations between the SOC and the long-term rain records. In the literatures on the SOC, power law distribution (scaling or scale invariance) is often used as a tool to prove a complexity dynamic process with the feature of SOC. To reveal the existing of SOC in the rain process, in the beginning we define a rain event as a sequence of consecutive nonzero measurements of the rain rate. Consequently, we use 3 variables, which contain rain duration, drought durations and accumulated rain amount to describe the feature of rain event in the region.

The probability density function of a physical variable $X$ (such as rain duration,drought duration and accumulated rain amount in a rainfall event) is denoted by $n(x)$, which 


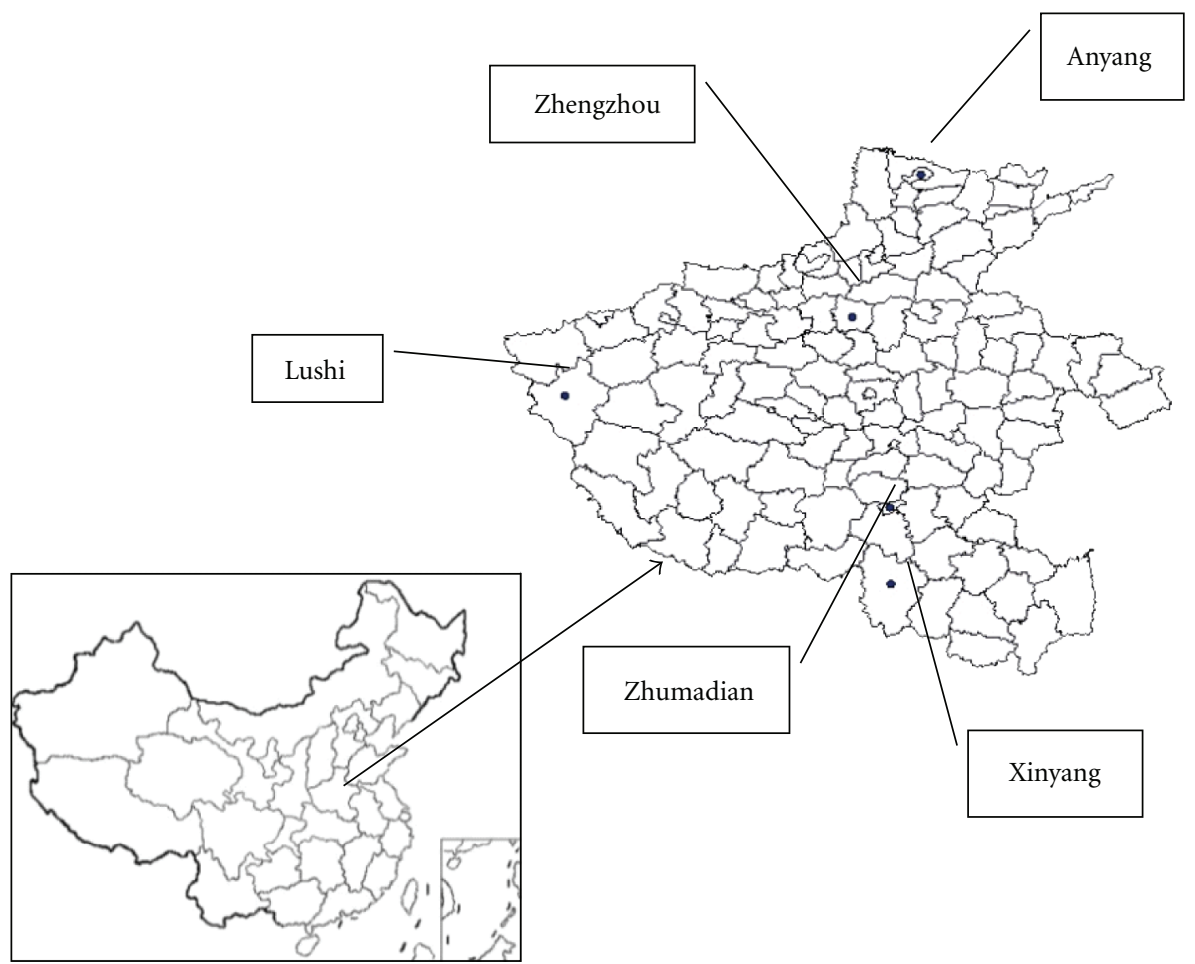

Figure 1: Distribution of stations, named Anyang, Zhengzhou, Lushi, Zhumadian, and Xinyang.

TABLE 1: Observation sites with station number, corresponding time periods estimated, and location.

\begin{tabular}{|c|c|c|c|c|}
\hline Site name & Station number & Operation period & \multicolumn{2}{|c|}{ Location } \\
\hline Zhengzhou & 57083 & $195101-200712$ & $34^{\circ} 43^{\prime} \mathrm{N}$ & $113^{\circ} 39^{\prime} \mathrm{E}$ \\
\hline Anyang & 53898 & 195102-200712 & $36^{\circ} 07^{\prime} \mathrm{N}$ & $114^{\circ} 22^{\prime} \mathrm{E}$ \\
\hline Zhumadian & 57290 & 195801-200712 & $33^{\circ} 00^{\prime} \mathrm{N}$ & $114^{\circ} 01^{\prime} \mathrm{E}$ \\
\hline Xinyang & 57297 & 195101-200712 & $32^{\circ} 08^{\prime} \mathrm{N}$ & $114^{\circ} 03^{\prime} \mathrm{E}$ \\
\hline Lushi & 57067 & 195207-200712 & $34^{\circ} 03^{\prime} \mathrm{N}$ & $111^{\circ} 02^{\prime} \mathrm{E}$ \\
\hline
\end{tabular}

Longitude and latitude of the location is represented as degree and minute.

accumulated probability distribution (PDF) is $\tilde{N}(x)$. PDF can be defined as

$$
\tilde{N}(x)=\int_{x}^{x_{M}} n(x) d x
$$

where $x_{M}$ is the maximum value in the data set. By using the integrated description instead of histograms we avoid data fluctuations in the low (high) value regime induced by the choice of logarithmic. If $n(x) \propto x^{-\tau}, x_{M} \rightarrow \infty$ and $\tau \rightarrow 1$, then $\tilde{N}(x) \propto x^{-\tau+1}$. Our rainfall data are generally confined to ranges $1<I<200$ days and $0.1 \mathrm{~mm}<x<400 \mathrm{~mm}$, while higher values are observed only in extreme situations. Therefore, we cannot replace $M$ by $\infty$ in (2) and obtain

$$
N(x)=\frac{\tilde{N}(x)}{x} \propto \frac{1}{x^{\tau}}\left[1-\left(\frac{x}{x_{M}}\right)^{\tau-1}\right] .
$$

Thus, the log-log plot of $N(x)$ versus $x$ definitely departs from a straight line as $x \rightarrow x_{M}$.
3.2. Algorithm. Based on the principle of scale invariant, we develop 2 algorithms corresponding to rain duration, drought duration and accumulated rain amount, in which first algorithm is about the former two items and the second is about the accumulated rain amount.

3.2.1. Procedure for Rain Duration and Drought Duration. Rain duration is the life time of a successive rainfall, and drought duration is the waiting time between two rain events. Let RD and DD stand for rain duration and drought, respectively. Their distribution densities are discrete which are listed as shown in Table 2.

To test the scaling of rain duration and drought duration in central China, analysis can be conducted by the following procedure.

Algorithm 1 (Accumulated probability distribution computation and plot of rain duration and drought duration). We have the following:

Step 1. Wash and treat the original data. 
TABLE 2: Distribution model of rain duration and drought duration.

\begin{tabular}{lcccc}
\hline RD/DD & $x_{1}$ & $x_{2}$ & $\cdots$ & $x_{M}$ \\
\hline$n(x)$ & $n\left(x_{1}\right)$ & $n\left(x_{2}\right)$ & $\cdots$ & $n\left(x_{M}\right)$ \\
$\tilde{N}(x)$ & $\sum_{i=1}^{M} n\left(x_{i}\right)$ & $\sum_{i=2}^{M} n\left(x_{i}\right)$ & $\cdots$ & $\sum_{i=M}^{M} n\left(x_{i}\right)$ \\
$N(x)$ & $\left(\sum_{i=1}^{M} n\left(x_{i}\right)\right) / x_{1}$ & $\left(\sum_{i=2}^{M} n\left(x_{i}\right)\right) / x_{2}$ & $\ldots$ & $\sum_{i=M}^{M} n\left(x_{i}\right) / x_{M}$ \\
\hline
\end{tabular}

$x_{i}$ stands for the length of every rain or drought event. $M$ is the longest time period.

Step 2. Plot the daily rain size on the rain date (see Figure 2).

Step 3. Count the numbers of every kind of rain events and assign $n(x)$ the number listed in the second row of Table 2.

Step 4. Calculate the accumulated number $\tilde{N}(x)=$ $\sum_{i=j}^{M} n\left(x_{i}\right), j=1,2, \ldots, M$ and list it in the third row.

Step 5. Calculate the number density $N(x)=\left(\sum_{i=j}^{M} n\left(x_{j}\right)\right) / x_{j}$ of rain event corresponding to the fourth row and list it in the fourth row.

Step 6. According to formula (3), we take the logarithm of the first and fourth row. By the linear regression technology, we will obtain $\tau$.

Step 7. Make the double-log distribution plot.

3.2.2. Procedure for Accumulated Rain Amount. In the present paper, the accumulated rain amount, which is symbolized as ARA, represents the total rain amount in a single rain event. Then, based on Step 1 and Step 2 in Algorithm 1, the procedure of ARA analysis can be followed by Algorithm 2 below.

Algorithm 2 (Accumulated probability distribution computation and plot of ARA). We have the following:

Step 1. By calculating the ARA we get a new ARA series $y_{1}, y_{2}, \ldots, y_{N}$, where $N$ stands for the number of the rainfall event in the long-term record.

Step 2. Let $y_{\min }=\min \left(y_{1}, y_{2}, \ldots, y_{N}\right), y_{\max }=\max \left(y_{1}, y_{2}\right.$, $\left.\ldots y_{N}\right)$, and partition the closed interval $\left[y_{\min }, y_{\max }\right]$ into subinterval $[y, y+\Delta y]$. Here, $\Delta y$ can be computed by using the following equation:

$$
\frac{y+\Delta y}{y}=10^{1 / 5} .
$$

Step 3. If $S$ is the number of all the subintervals, we calculate the times of the occurrences of $y_{1}, y_{2}, \ldots y_{N}$ in every interval and note them $n(s), s=1,2, \ldots, S$.

Step 4. Calculate the accumulated number $\tilde{N}(s)=\sum_{s=j}^{S} n(s)$, $j=1,2, \ldots S$.

Step 5. Calculate the number density $N(s)=\left(\sum_{s=j}^{S} n(s)\right) /$ $\Delta s_{j}$
Step 6. Take the logarithm of $N(s)$ and left end point of $[y, y+\Delta y]$. By the linear regression technology, we will obtain $\tau$ in terms of Formula (3).

Step 7. Make the double-log distribution plot.

\section{Result and Discussion}

According to the steps of Algorithm 1, the long-term rains are shown in Figure 2. Xinyang station and Zhumadian station, which are located in the southern part of Henan Province, are plotted above. Contrast Anyang station, Zhenzhou station, and Lushi station, which are located in the northern part of this province.

4.1. Rain Duration and Drought Duration. Corresponding to Table 2, the calculation results of rain duration are listed in Table 3. For the dataset is too large, here we only list out Zhenzhou station's data.

The computation results about rain duration and drought duration show that the rainfall times and the rain duration, the drought days and the drought duration exhibit the power law relation. Taking the logarithm value of number density as the vertical axis and the logarithm value of the rain duration as horizontal axis, we find that the distribution of the rain duration number in Xinyang station, Zhumadian station, Zhengzhou station, and Lushi station is similar with their function profile (see Figure 3) while Anyang's number density of rain duration exhibits the different feature. The scale-free region ranges from 1 to 10 in Anyang and from 1 to 11 in other places. Here, $\tau_{\text {anyang }}=-1.35$, other $\tau \mathrm{s}$ fluctuate around -1.68 . Influenced by the monsoon climate, the rain season begins in the early June and ends in the lately September. In fact, the Anyang is this region where the rain duration is the shortest in Henan province.

Looking at Figure 3 and Figure 4, it seems that the number density of drought duration displays the same distribution characteristics with the rain durations. Actually, the number density of rain duration is different in some aspects, such as the maximum time period and scaleless region. Furthermore, attention should be paid to the number density of drought duration in Zhengzhou and Anyang (see Figure 5). The scale region of Anyang station ranges from 1 day to 100 days, and Zhengzhou's scaling left end point closes to 100 but Xingyang's and Zhumadian's are about 50 .

Here, $\tau_{\text {xinyang }}, \tau_{\text {xinyang }} \approx-1.71$, and other $\tau$ is about -1.5 . 

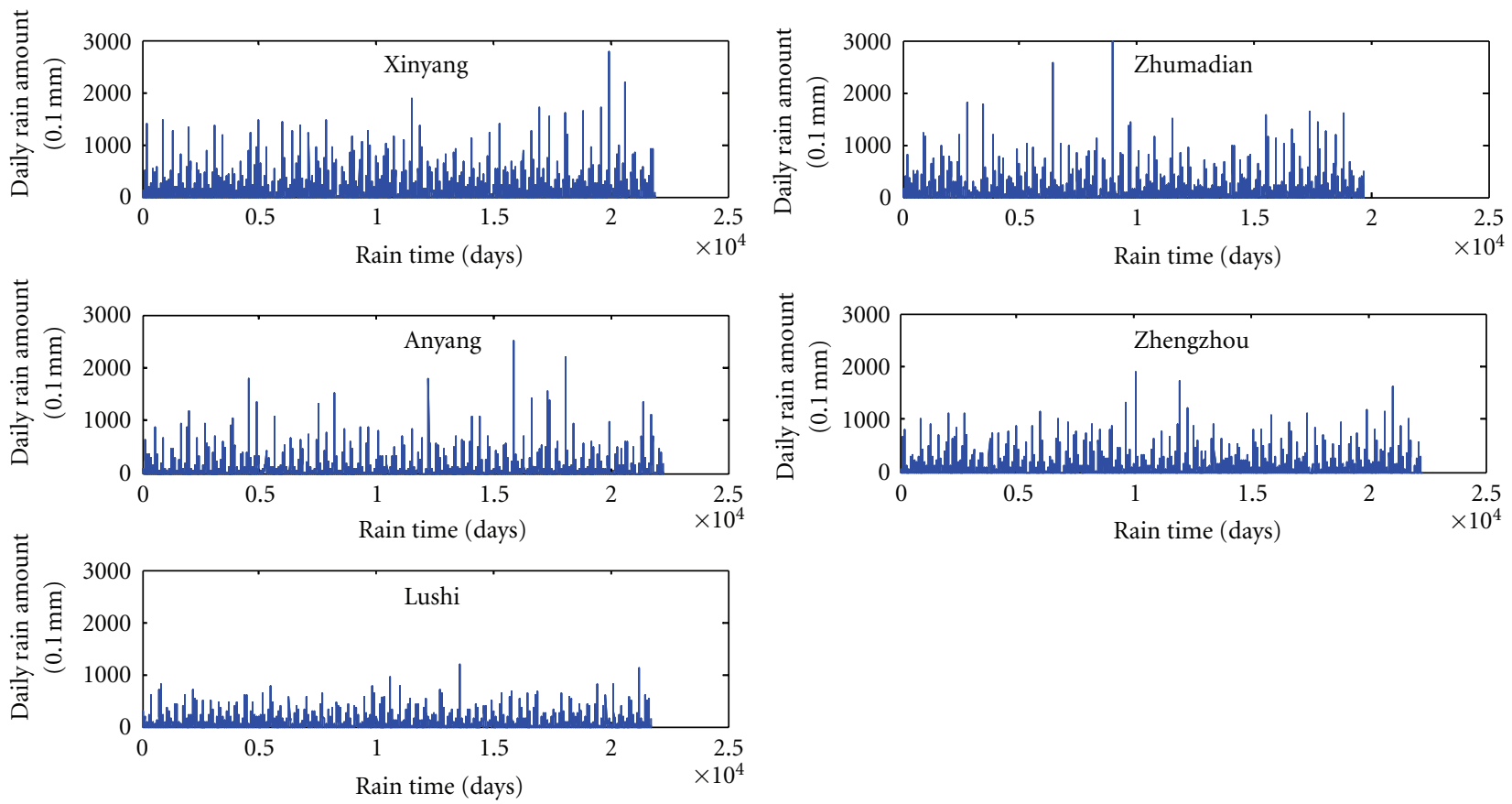

FIGURE 2: Plot of five rain series in Henan province.
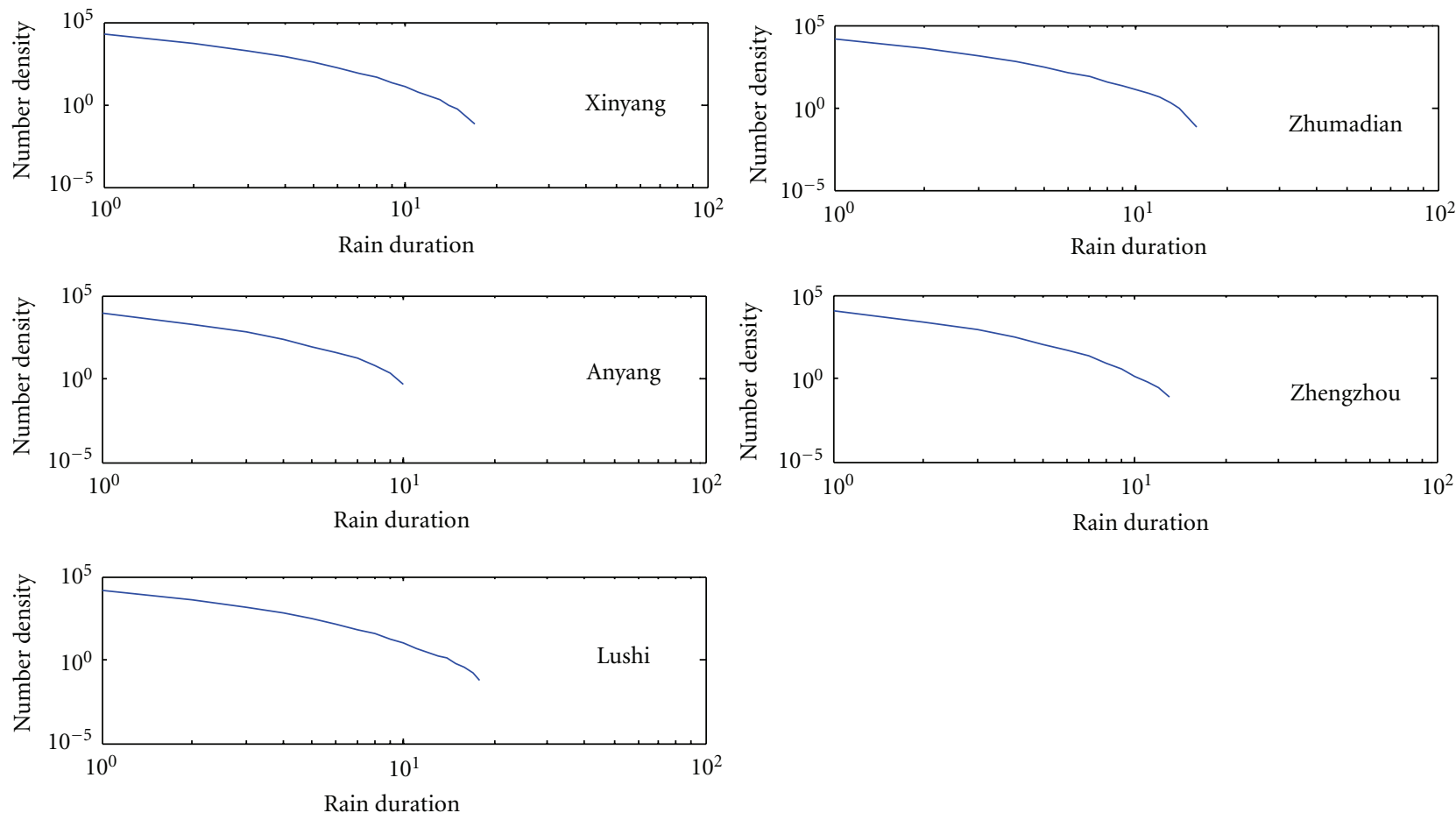

Figure 3: Log-log plot of the probability number density for rain duration.

4.2. Accumulated Rain Amount. Comparing with the analysis on rain duration and drought duration, it is more difficult to understand the behavior characteristics of long-term ARA dynamics process. To test if the ARA is scale invariant, we calculated the ARA number density in the partitioned intervals in terms of Algorithm 2.
The results show that all five series follow the power law relation in the scale range from $0.1 \mathrm{~mm}$ to $60 \mathrm{~mm}$. Here $\tau_{\text {xingyang }}=-1.61, \tau_{\text {zhumadian }}=-1.63, \tau_{\text {anyang }}=$ $-1.72, \tau_{\text {zhengzhou }}=-1.52, \tau_{\text {lushi }}=-1.55$. The ARA number density distributions of Xinyang and Zhumadian displays the similar profile since they are in the same 

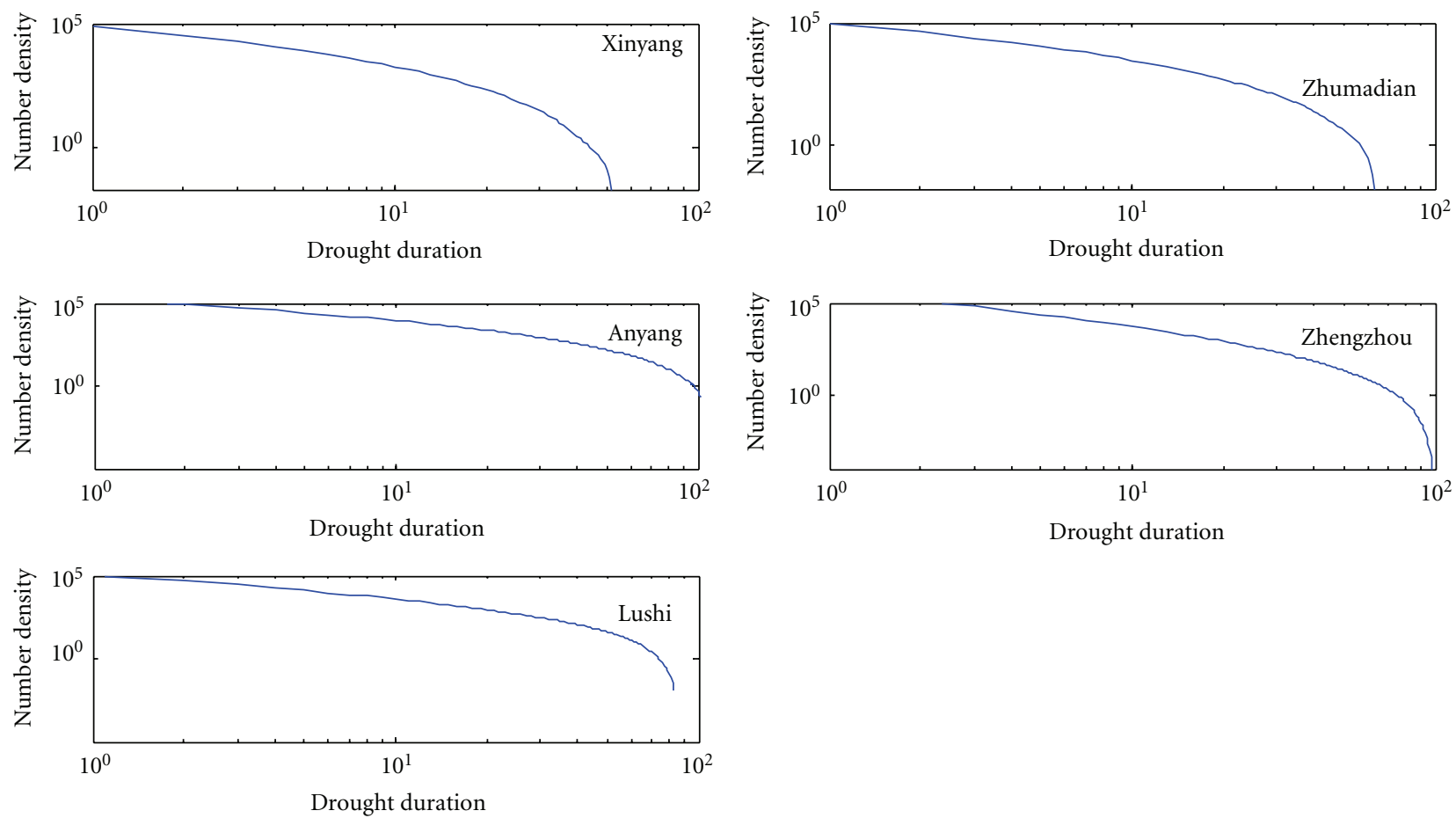

FIgURE 4: Log-log plot of the probability number density for drought duration.
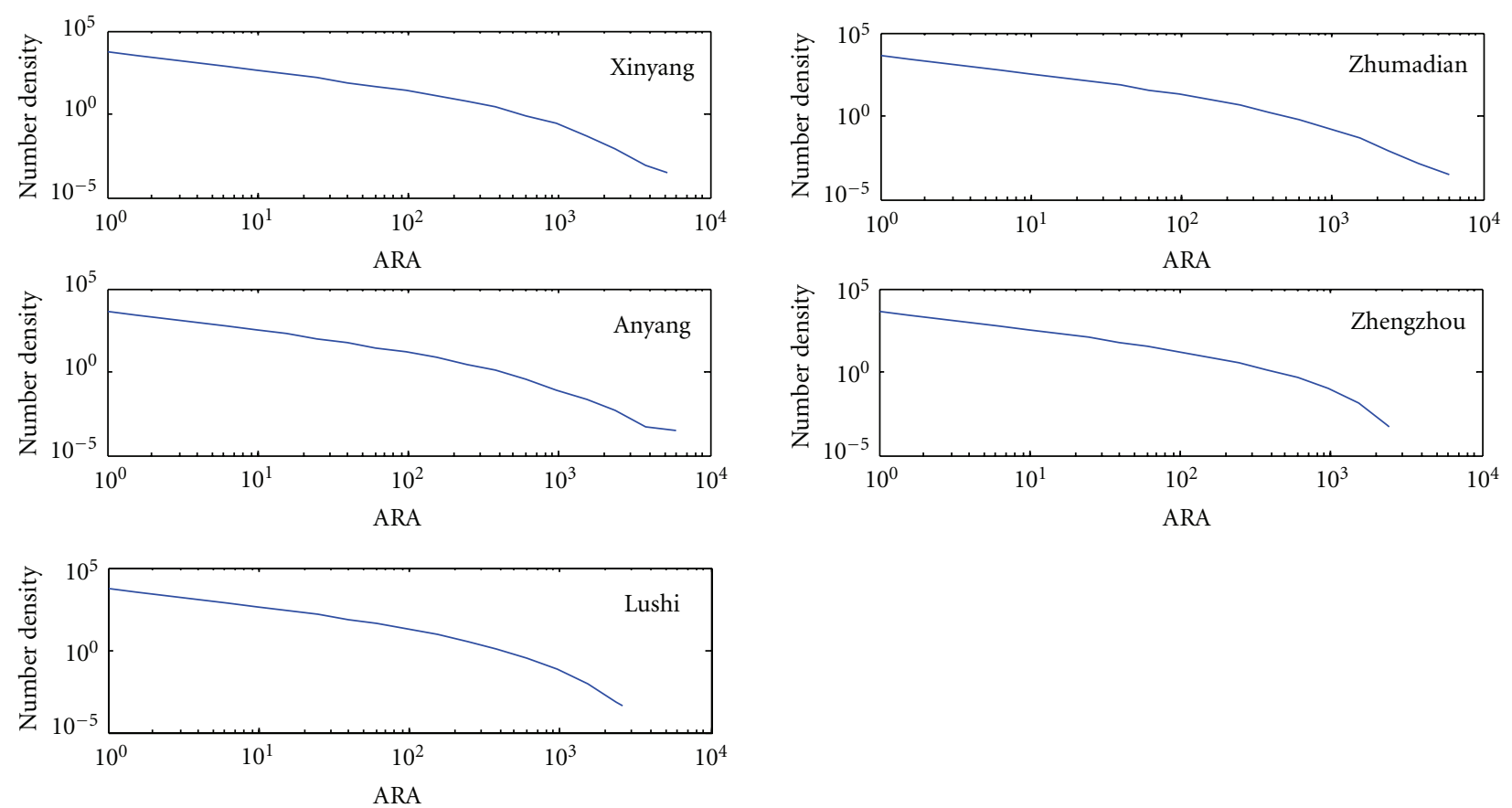

FIGURE 5: Log-log plot of the probability number density for accumulated rain amount.

climate classification region, the subtropical zone. Like Section 4.1, the feature of ARA in Anyang station is also different from the other stations. Although Lushi station is located in the western mountain region, however, the ARA behavior characteristic in Zhengzhou station is similar to it.
4.3. Discussion. In Sections 4.1 and 4.2 we have investigated the long-term series of precipitation records and succeeded in finding the evidence for power law distribution even though the five stations are located in different position in central China. This implies that our guess (i.e., the rainfall in central China takes on the feature of SOC) is right. This also 
TABLE 3: Days of RD and DD; ARA (in $0.1 \mathrm{~mm}$ ) per rain event.

\begin{tabular}{|c|c|c|c|c|c|c|c|c|c|c|c|}
\hline $\mathrm{RD}$ & $N(\mathrm{RD})$ & $\mathrm{DD}$ & $N(\mathrm{DD})$ & $\mathrm{DD}$ & $N(\mathrm{DD})$ & S.N & ARA & S.N & ARA & S.N & ARA \\
\hline 1 & 4309 & 1 & 14586 & 37 & 44 & 1 & 48 & 37 & 92 & $\cdots$ & $\cdots$ \\
\hline 2 & 2427 & 2 & 11564 & 38 & 35 & 2 & 92 & 38 & 42 & 2501 & 15 \\
\hline 3 & 1418 & 3 & 9553 & 39 & 27 & 3 & 7 & 39 & 18 & 2502 & 60 \\
\hline 4 & 812 & 4 & 7615 & 40 & 21 & 4 & 61 & 40 & 55 & 2503 & 1 \\
\hline 5 & 463 & 5 & 6205 & 41 & 17 & 5 & 39 & 41 & 14 & 2504 & 212 \\
\hline 6 & 257 & 6 & 5084 & 42 & 13 & 6 & 8 & 42 & 20 & 2505 & 26 \\
\hline 7 & 141 & 7 & 4179 & 43 & 11 & 7 & 6 & 43 & 88 & 2506 & 80 \\
\hline 8 & 78 & 8 & 3448 & 44 & 9 & 8 & 3 & 44 & 1 & 2507 & 9 \\
\hline 9 & 42 & 9 & 2868 & 45 & 8 & 9 & 42 & 45 & 320 & 2508 & 66 \\
\hline 10 & 26 & 10 & 2425 & 46 & 7 & 10 & 35 & 46 & 95 & 2509 & 297 \\
\hline 11 & 17 & 11 & 2072 & 47 & 6 & 11 & 75 & 47 & 56 & 2510 & 60 \\
\hline 12 & 10 & 12 & 1783 & 48 & 5 & 12 & 58 & 48 & 296 & 2511 & 8 \\
\hline 13 & 6 & 13 & 1542 & 49 & 4 & 13 & 780 & 49 & 68 & 2512 & 10 \\
\hline 14 & 4 & 14 & 1333 & 50 & 3 & 14 & 85 & 50 & 38 & 2513 & 18 \\
\hline 15 & 2 & 15 & 1161 & 51 & 2 & 15 & 7 & 51 & 93 & 2514 & 53 \\
\hline 16 & 1 & 16 & 1105 & 52 & 1 & 16 & 278 & 52 & 16 & 2515 & 51 \\
\hline 17 & 0 & 17 & 879 & 53 & 0 & 17 & 44 & 53 & 25 & 2516 & 223 \\
\hline 18 & 0 & 18 & 762 & 54 & 0 & 18 & 468 & 54 & 121 & 2517 & 299 \\
\hline 19 & 0 & 19 & 660 & 55 & 0 & 19 & 18 & 55 & 1 & 2518 & 66 \\
\hline 20 & 0 & 20 & 566 & 56 & 0 & 20 & 555 & 56 & 653 & 2519 & 437 \\
\hline 21 & 0 & 21 & 486 & 57 & 0 & 21 & 50 & 57 & 43 & 2520 & 213 \\
\hline 22 & 0 & 22 & 421 & 58 & 0 & 22 & 59 & 58 & 30 & 2521 & 104 \\
\hline 23 & 0 & 23 & 365 & 59 & 0 & 23 & 34 & 59 & 29 & 2522 & 11 \\
\hline 24 & 0 & 24 & 317 & 60 & 0 & 24 & 21 & 60 & 79 & 2523 & 605 \\
\hline 25 & 0 & 25 & 278 & 61 & 0 & 25 & 213 & 61 & 52 & 2524 & 381 \\
\hline 26 & 0 & 26 & 241 & 62 & 0 & 26 & 225 & 62 & 237 & 2525 & 1561 \\
\hline 27 & 0 & 27 & 211 & 63 & 0 & 27 & 13 & 63 & 1 & 2526 & 237 \\
\hline 28 & 0 & 28 & 187 & 64 & 0 & 28 & 96 & 64 & 21 & 2527 & 355 \\
\hline 29 & 0 & 29 & 164 & 65 & 0 & 29 & 11 & 65 & 8 & 2528 & 125 \\
\hline 30 & 0 & 30 & 143 & 66 & 0 & 30 & 2 & 66 & 384 & 2529 & 267 \\
\hline 31 & 0 & 31 & 125 & 67 & 0 & 31 & 812 & 67 & 47 & 2530 & 398 \\
\hline 32 & 0 & 32 & 109 & 68 & 0 & 32 & 198 & 68 & 7 & 2531 & 422 \\
\hline 33 & 0 & 33 & 95 & 69 & 0 & 33 & 7 & 69 & 15 & 2532 & 25 \\
\hline 34 & 0 & 34 & 81 & 70 & 0 & 34 & 146 & 70 & 111 & 2533 & 0 \\
\hline 35 & 0 & 35 & 68 & 71 & 0 & 35 & 189 & 71 & 71 & 2534 & 0 \\
\hline 36 & 0 & 36 & 56 & 72 & 0 & 36 & 8 & 72 & 76 & 2535 & 0 \\
\hline
\end{tabular}

supports the view that atmospheric dynamics is governed, at least in part, by SOC.

As described in the introduction, the concept of SOC refers to the state of nonequilibrium systems driven by slow constant energy input to organize themselves into critical systems. The intermediately stored energy is eventually released in sudden bursts with no typical scale. From this point of view, rainfall events which occur in the central China are not very different from those ones in the other place. Like earthquakes, a rainfall event is driven by a slow and constant energy input from the sun and water is evaporated from the Western Pacific Ocean. The energy is stored in the form of water vapor in the atmosphere. It is then suddenly released in bursts when the vapors condense to water drops. The power-law distribution of the number density of rain events is equivalent to the Gutenberg-Richter law for earthquakes.

Although there are different geographic coordinates at the five stations, these $\tau$ s show little change because the five stations are neighborhoods in one province after all. Except for the topography and landform the driving factors of rainfall, such as the sun radiation and the pattern of atmospheric circulation are nearly the same.

\section{Conclusion}

Testing the hypothesis, the existence of self-organized criticality in the long rain process in central China is our objective in this work. By calculating the number density of the rain 
duration, the drought duration, and the accumulated rain amount, we found that the relationship between the number density functions and rain duration, drought duration and accumulated amount exhibits the feature of power law. In other words, we have looked out the evidence of selforganized criticality in the long-term rain processes in central region of China. It is turned out that the long dry and wet process is indeed the complexity dynamics process.

Henan province is in the climate transition zone where the climate changes from the southern humid subtropical monsoon region to the northern semiarid temperature monsoon. It is also the topography transition zone. The western region is mountain and the eastern is the great plain. Because of these reasons, the weather and the climate change drastically in a year and interyears. This point has also been turned out from our results and plots. The feature of wet and dry spell is significantly different between Anyang station and Xinyang station.

In this work we only studied five meteorological stations due to the limitation of datasets. And the minimum time interval is a day which appears to be not small enough for the analysis of rainfall event. We will therefore collect more data sets in central China and other regions in the future work. The self-organized criticality needs to be tested in a small temporal interval and in a larger spatial scale, such as in the level of hour or second and in the level of the whole country. Furthermore, Algorithm 2 proposed should be improved on the number density computation of accumulated rain amount. The concept of number density of duration and intension should be redefined over and over again in the future work.

\section{Acknowledgments}

This work was founded by the Technologies R \& D Program of Zhengzhou (Grant no. 0910SGYG21201-6, 43204-522) and Educational Commission of Henan Province of China (4113-521). The authors would like to thank Dr. Yanling Li for the helpful assistance. They thank their anonymous referees for their valuable comments and suggestions.

\section{References}

[1] J. Jiang, D. Zhang, and K. Fraedrich, "HIstoric climate variability of wetness in east China (960-1992): a wavelet analysis," International Journal of Climatology, vol. 17, no. 9, pp. 969981, 1997.

[2] I. Bordi, K. Fraedrich, J. M. Jiang, and A. Sutera, "Spatiotemporal variability of dry and wet periods in eastern China," Theoretical and Applied Climatology, vol. 79, no. 1-2, pp. 8191, 2004.

[3] Q. Wang, X. Liu, and A. Fang, "Mathematical model of rain fall forecast," in Proceedings of the ETP International Conference on Future Computer and Communication (FCC '09), pp. 112115, 2009.

[4] P.-S. Yu, C.-J. Chen, and S.-J. Chen, "Application of gray and fuzzy methods for rainfall forecasting," Journal of Hydrologic Engineering, vol. 5, no. 4, pp. 339-345, 2000.

[5] I. Rodriguez-Iturbe, B. Febres De Power, M. B. Sharifi, and K. P. Georgakakos, "Chaos in rainfall," Water Resources Research, vol. 25, no. 7, pp. 1667-1675, 1989.
[6] Z. Wang and W. Li, "Prediction of monthly precipitation in Kunming based on the chaotic time series analysis," in Proceedings of the 4th Annual Meeting of Risk Analysis Council of China Association for Disaster Prevention, Atlantis Press, 2010.

[7] Z. Wang and Y. Zhang, "Chaos analysis of time series of kunming annual precipitation," Journal of North China Institute of Water Conservancy and Hydroelectric Power, vol. 32, 2, pp. 8-10, 2011.

[8] S. Bellie, S.-Y. Liong, and C.-Y. Liaw, "Evidence of chaotic behavior in Singapore rainfall," Journal of the American Water Resources Association, vol. 34, 2, pp. 301-310, 1998.

[9] B. Sivakumar, S.-Y. Liong, C.-Y. Liaw, and K.-K. Phoon, "Singapore rainfall behavior: Chaotic?" vol. 4, no. 1, pp. 3848, 1999.

[10] M. C. Valverde Ramírez, H. F. De Campos Velho, and N. J. Ferreira, "Artificial neural network technique for rainfall forecasting applied to the São Paulo region," Journal of Hydrology, vol. 301, no. 1-4, pp. 146-162, 2005.

[11] P. Bak, How Nature Works: The Science of Self-Organized Criticality, Springer, New York, NY, USA, 1996.

[12] P. Bak and S. Boettcher, "Self-organized criticality and punctuated equilibria," Physica D, vol. 107 , no. $2-4$, pp. 143-150, 1997.

[13] P. Bak, C. Tang, and K. Wiesenfeld, "Self-organized criticality: An explanation of the 1/f noise," Physical Review Letters, vol. 59, no. 4, pp. 381-384, 1987.

[14] C. Tang and P. Bak, "Critical exponents and scaling relations for self-organized critical phenomena," Physical Review Letters, vol. 60, no. 23, pp. 2347-2350, 1988.

[15] K. Christensen, Z. Olami, and P. Bak, "Deterministic 1/f noise in nonconserative models of self-organized criticality," Physical Review Letters, vol. 68, no. 16, pp. 2417-2420, 1992.

[16] S. C. Manrubia and R. V. Solé, "Self-organized criticality in rainforest dynamics," Chaos, Solitons and Fractals, vol. 7, no. 4, pp. 523-541, 1996.

[17] A. Sarkar and P. Barat, "Analysis of rainfall records in India: self-organized criticality and scaling," Fractals, vol. 14, no. 4, pp. 289-293, 2006.

[18] P. Lehmann and D. Or, "Concepts of Self-Organized Criticality for modeling triggering of shallow landslides," Geophysical Research Abstracts, vol. 10, no. 2, 2008.

[19] M. J. Van De Wiel and T. J. Coulthard, "Self-organized criticality in river basins: challenging sedimentary records of environmental change," Geology, vol. 38, no. 1, pp. 87-90, 2010.

[20] O. Peters and K. Christensen, "Rain viewed as relaxational events," Journal of Hydrology, vol. 328, no. 1-2, pp. 46-55, 2006.

[21] O. Peters and J. D. Neelin, "Critical phenomena in atmospheric precipitation," Nature Physics, vol. 2, no. 6, pp. 393396, 2006.

[22] R. F. S. Andrade, H. J. Schellnhuber, and M. Claussen, "Analysis of rainfall records: possible relation to self-organized criticality," Physica A, vol. 254, no. 3-4, pp. 557-568, 1998.

[23] O. Peters and K. Christensen, "Rain: relaxations in the sky," Physical Review E, vol. 66, no. 3, Article ID 036120, 9 pages, 2002.

[24] O. Peters, C. Hertlein, and K. Christensen, "A complexity view of rainfall," Physical Review Letters, vol. 88, no. 1, Article ID 018701, 4 pages, 2002.

[25] G. Pruessner and O. Peters, "Self-organized criticality and absorbing states: lessons from the Ising model," Physical Review E, vol. 73, no. 2, Article ID 025106, 4 pages, 2006. 

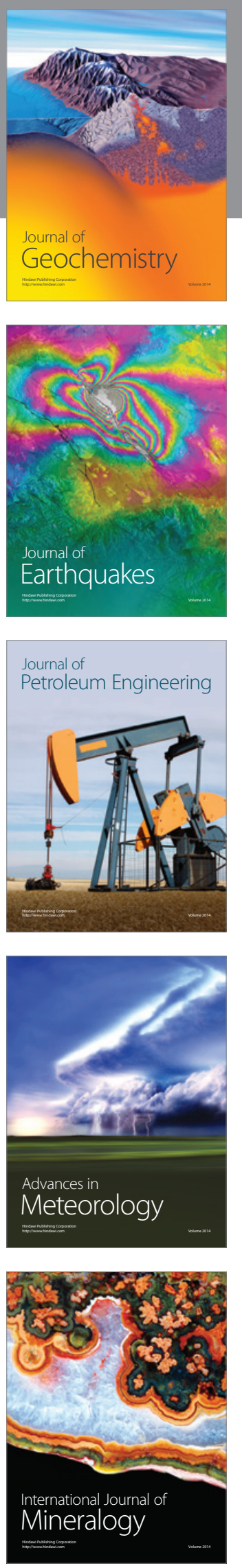
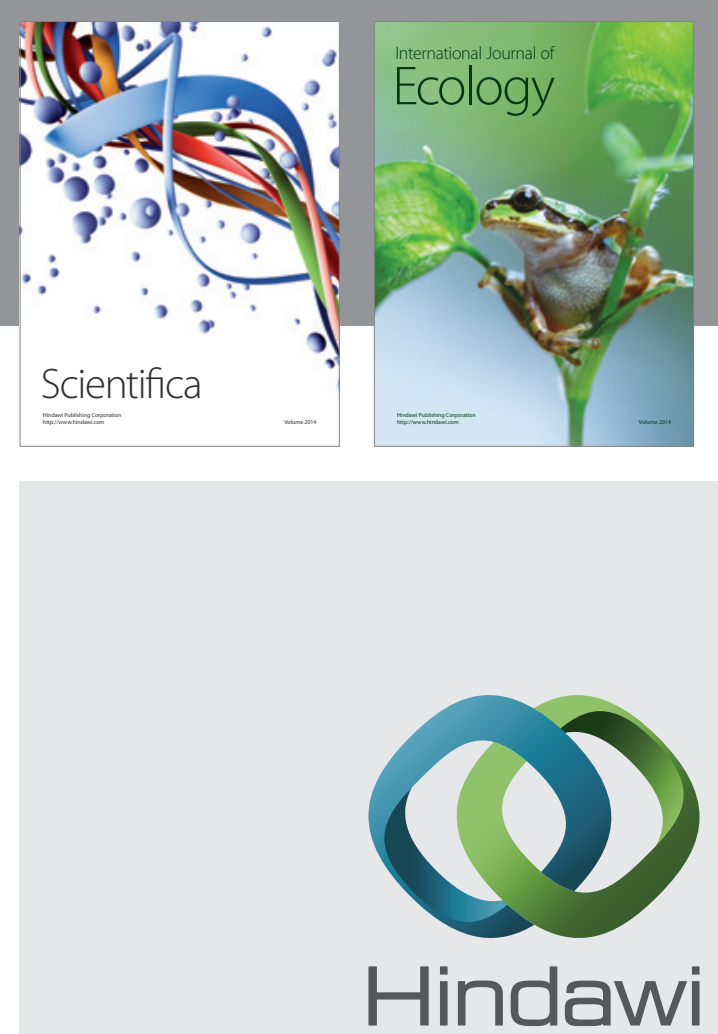

Submit your manuscripts at http://www.hindawi.com
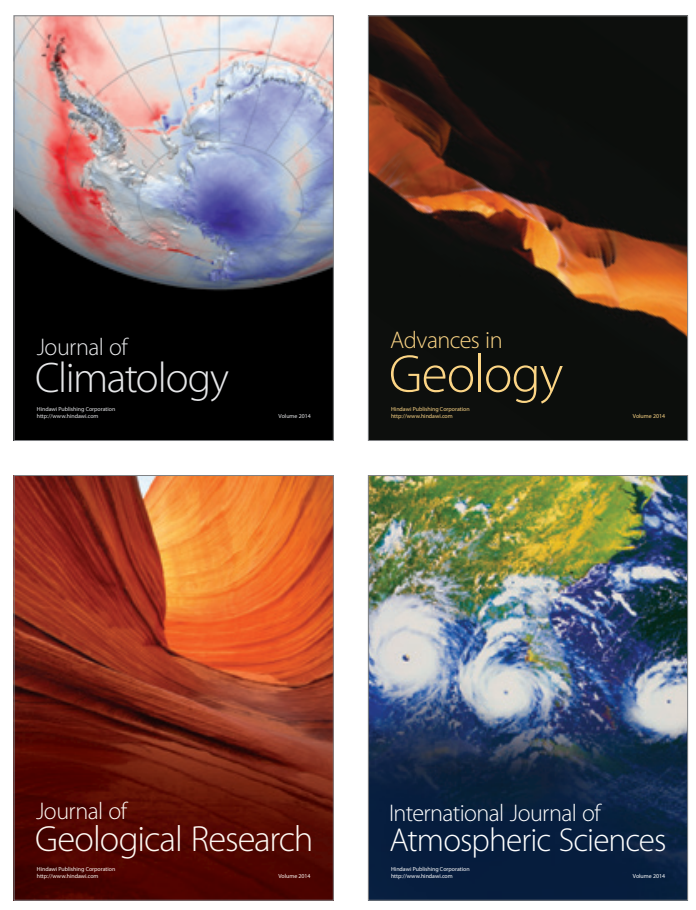
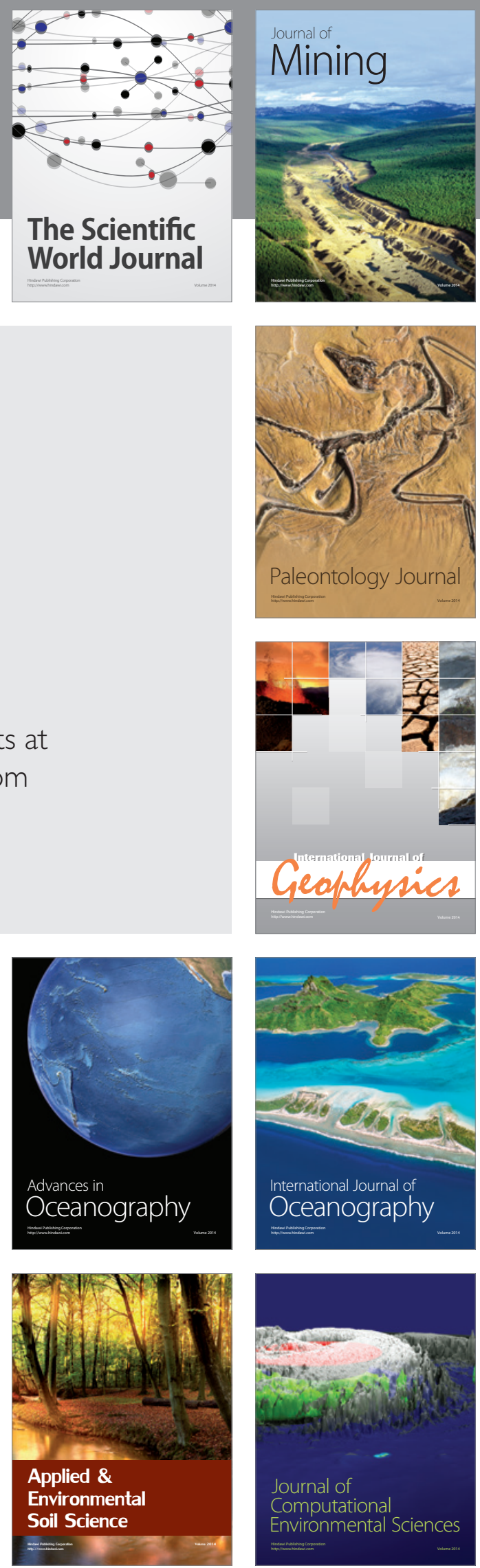